\title{
Sentidos docentes: (des) ensino da língua portuguesa no ensino médio
}

\author{
Teacher Senses: (un)teaching the Portuguese language in high school \\ Rosangela Vargas Cassola ${ }^{1}$ \\ Faculdade de Tecnologia Senai Campo Grande
}

\begin{abstract}
- RESUMO: O ensino da disciplina de Língua Portuguesa no ensino médio tem sido motivo de debates teóricos e metodológicos, por conta dos resultados apresentados, desde a última década, por alguns sistemas de avaliação educacional tais como o ENEM - Exame Nacional do Ensino Médio e o SAEB - Sistema de Avaliação da Educação Básica. No estado do Mato Grosso do Sul, mudanças significativas estão sendo implantadas, a exemplo das recentes alterações na Matriz Curricular do Ensino Médio na Rede Estadual de Ensino. Assim, nossa pesquisa de caráter qualitativointerpretativista, por meio da Análise do Discurso (Orlandi (2012), Pêcheux (1990)) objetiva analisar os sentidos docentes acerca do ensino da Língua Portuguesa no Ensino Médio. Espera-se ao final da pesquisa compreender os sentidos docentes acerca do ensino da Língua Portuguesa no Ensino Médio, acerca da divisão da Língua Portuguesa na Matriz Curricular do Ensino Médio em Língua Portuguesa I e Língua Portuguesa II (Resolução SED/MS 3098/2016), da extinção das unidades curriculares Língua Portuguesa II e Literatura da Matriz Curricular do Ensino Médio (Resolução SED/MS 3196/2017) e ainda, da possibilidade de aplicabilidade do Referencial Curricular da Rede Estadual de Ensino do Mato Grosso do Sul - Ensino Médio.

- PALAVRAS-CHAVE: Língua portuguesa. Análise do discurso. Docentes.
\end{abstract}

- ABSTRACT: The Portuguese Language teaching in High School has been the subject of theoretical and methodological debates, due to the results presented, since the last decade, by some educational evaluation systems such as ENEM - Brazilian High School Examination and SAEB Basic Education Evaluation System. In the state of Mato Grosso do Sul, significant changes are being implemented, for instance with recent modifications in the High School Curriculum in the State Education Network. Therefore, our qualitative-interpretative research, through the discourse analysis (Orlandi (2012), Pêcheux (1990)) aims to analyze the teachers' senses on Portuguese Language teaching in High School. The goal of this research is to understand the teachers' senses regarding the Portuguese Language teaching in High School, the division of the Portuguese Language in the High School Curriculum into Portuguese Language I and Portuguese Language II (Resolution SED / MS 3098/2016), the extinction of course units Portuguese Language II and Literature from High School Curriculum (Resolution SED / MS 3196/2017) and also the potential applicability of the High School Curriculum Framework of Mato Grosso do Sul State Education Network.

- KEYWORDS: Portuguese Language. Discourse analysis. Teachers.

\section{Introdução}

O manuscrito a seguir, trata-se da apresentação realizada durante a abertura no V Encontro em Análise do Discurso: Estudos Orlandianos e no III ENSAD - Encontro Nacional em Semântica e Análise do Discurso: Marcha, Identidade e Fronteira, ocorridos na Universidade Estadual do Mato Grosso do Sul, em Campo Grande, em junho de 2017. Apresentou-se na mesa de abertura dos trabalhos, a pesquisa vinculada ao estágio acadêmico pós-doutoral junto ao Programa de Pós-graduação em Letras da

\footnotetext{
1 Doutora em Linguística Aplicada e Estudos da Linguagem pela PUC/SP. NEAD/FATEC/MS. rcassola@brturbo.com.br
} 
Universidade Estadual de Mato Grosso do Sul. A pesquisa intitulada "Sentidos docentes: (des) ensino da Língua Portuguesa no ensino médio", a qual objetiva analisar os sentidos docentes atribuídos ao ensino da Língua Portuguesa no Ensino Médio, possibilitou aos participantes do evento a análise do funcionamento dos enunciados e ainda, a compreensão da materialização dos discursos na prática social através das marcas discursivas. Inserida na Análise do Discurso, a pesquisa terá como base material o corpus da representação do discurso de professores de Língua Portuguesa que ministram aulas no ensino médio em três escolas estaduais. A escolha das escolas será aleatória, porém o lócus será em uma escola da área urbana, uma da área rural e uma escola indígena no município de Campo Grande-MS.

\section{Revisão da literatura}

A perspectiva teórica adotada é a Análise do Discurso Francesa, bem como os pressupostos da filosofia da linguagem/teoria anunciativa da língua de Mikhail Bakhtin. Bakhtin (2011). A qual compreende que a realidade fundamental da linguagem é a atividade humana inter-relacionada à sociedade, na qual os indivíduos socialmente organizados são constituídos em relações sociais das quais participam de forma ativa e responsiva. $\mathrm{O}$ uso da língua efetivado em forma de enunciados concretos, "unidade real da comunicação discursiva" (BAKHTIN, 2011, p.269), relaciona-se a diferentes situações comunicativas da vida, de forma que a língua integra a vida e constitui os sujeitos por meio dos enunciados que a realizam.

Assim, considerando que a língua integra a vida e constitui os sujeitos por meio dos enunciados, a pesquisa em desenvolvimento fará um exercício dialógico, onde estarão em jogo as vozes escritas dos docentes autores das materialidades a serem analisadas, a partir dos estudos de Bakhtin e o Círculo e da Análise do Discurso.

Segundo Bakhtin, nosso entorno é permeado das vozes de outras pessoas, vozes são palavras no sentido de enunciados. Depreende-se dos estudos de Bakhtin (1992), que o sentido de uma palavra é construído a partir de uma situação histórica que permitirá entender o enunciado, o querer dizer, a significação da palavra. Para ele, um mesmo enunciado, em situações distintas, pode remeter a inúmeros sentidos. Considerase que a atribuição de sentido que o docente remete ao ensino da língua portuguesa, pode ser resgatado a partir de suas palavras.

A palavra do outro é imprescindível na construção do 'eu', a linguagem é percebida a partir de uma concepção dialógica, uma vez que toda palavra comporta duas faces: de um lado, sempre procede de alguém e, de outro, dirige-se a alguém. Dessa forma, a palavra "[...] constitui justamente o produto da interação do locutor e do ouvinte. Toda palavra serve de expressão de um em relação ao outro. Através da palavra, "defino-me em relação ao outro" (BAKHTIN; VOLOSHINOV, 1992, p.113).

Para Bakhtin (1992, p. 128), as palavras são impregnadas de sentido, "um sentido definido e único, é uma propriedade que pertence a cada enunciação como um todo". O sentido é o significado contextual que aparece no livro Marxismo e Filosofia da Linguagem como tema, ele chama o sentido completo de tema. Nas palavras de Bakhtin (1992, p. 132). "o tema da enunciação é determinado não só pelas formas linguísticas que entram na composição (as palavras, as entonações, as formas morfológicas ou sintáticas, os sons, as entonações), mas igualmente pelos elementos não verbais da situação". O tema da enunciação para Bakhtin é "individual e não reiterável", pois é ele que origina a enunciação por se apresentar "como expressão de uma situação concreta", uma enunciação toda vez que for proferida trará consigo sentidos diferentes. Os sentidos só podem se constituir se houver a materialidade 
linguística ou, seja, a interação e a produção de sentidos ocorrem através de enunciados efetivamente ditos. Porém, antes da compreensão da definição de enunciado, precisa-se entender que "discurso" são os valores e conhecimentos dos indivíduos, enquanto sujeitos sociais, e estes, só podem manifestar-se através de enunciados, isto é, aquilo que é efetivamente dito em um processo de enunciação concreta. $\mathrm{O}$ discurso e o enunciado estão interligados, assim, a real unidade da comunicação discursiva é o enunciado. Para Bakhtin:

[...] todo enunciado concreto é um elo na cadeia da comunicação discursiva de um determinado campo. Os próprios limites do enunciado são determinados pela alternância dos sujeitos do discurso. Os enunciados não são diferentes entre si, nem se bastam cada um a si mesmos; uns conhecem os outros e se refletem mutuamente uns nos outros [...]. Cada enunciado é pleno de ecos e ressonâncias de outros enunciados com os quais está ligado pela identidade da esfera de comunicação discursiva. Cada enunciado deve ser visto antes de tudo como uma resposta aos enunciados precedentes de um determinado campo [...]: ele os rejeita, confirma, completa, baseia-se neles, subentende-os como conhecidos, de certo modo os leva em conta. (BAKHTIN, 2011, p. 296-297).

Para Orlandi (2007), discurso não se trata de transmissão de informação. Não é simplesmente um processo linear, onde um fala e o outro assimila, não é sequencial, um fala o outro decodifica a mensagem. Para o analista de discurso, o objeto é o discurso. Por conta disso, o alinhamento da pesquisa "Sentidos docentes: (des) ensino da Língua Portuguesa no ensino médio", com esta linha teórica.

A Análise de Discurso, como seu próprio nome indica, não trata da língua, não trata da gramática, embora todas essas coisas lhe interessem. Ela trata do discurso. E a palavra discurso, etimologicamente, tem em si a ideia de curso, de percurso, de correr por, de movimento. $\mathrm{O}$ discurso é assim palavra em movimento, prática de linguagem: com o estudo do discurso observa-se o homem falando (ORLANDI, 2007, p. 15).

\section{Objetivos}

O objetivo geral da pesquisa "Sentidos docentes: (des) ensino da Língua Portuguesa no ensino médio", é analisar os sentidos docentes acerca do ensino da Língua Portuguesa no Ensino Médio. No que concerne aos objetivos específicos, podese citar 3:

1. Analisar os sentidos docentes provenientes dos discursos dos professores acerca da divisão da Língua Portuguesa na Matriz Curricular do Ensino Médio em Língua Portuguesa I e Língua Portuguesa II (Resolução SED/MS 3098 publicada em 05 de outubro de 2016). 
ANEXO II DA RESOLUÇÃO/SED N. 3.098, DE 30 DE SETEMBRO DE 2016.

MATRIZ CURRICULAR DO ENSINO MÉDIO

Ano: a partir de 2017

Turno: diurno e noturno

Semana letiva: 5 (cinco) dias

Duração da aula: 50 (cinquenta) minutos

Duração do ano letivo: 200 (duzentos) dias

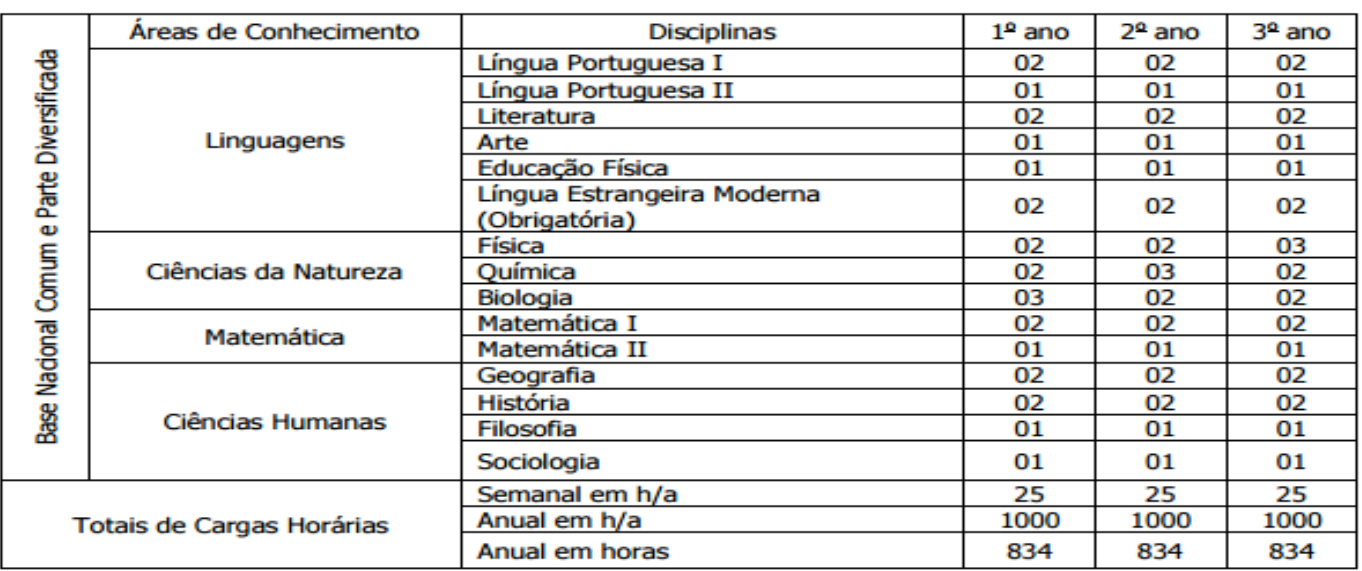

Fonte: http://www.spdo.ms.gov.br/diariodoe/Index/Download/DO9263_05_10_2016

2. Analisar os sentidos docentes provenientes dos discursos dos professores acerca da extinção das unidades curriculares Língua Portuguesa II e Literatura da Matriz Curricular do Ensino Médio (Resolução SED/MS 3196 publicada em 31 de janeiro de 2017).

ANEXO III DA RESOLUÇÃO/SED N. 3.196, DE 30 DE JANEIRO DE 2017.

MATRIZ CURRICULAR DO ENSINO MÉDIO

Ano: a partir de 2017

Turno: diurno e noturno

Semana letiva: 5 (cinco) dias

Duração da aula: 50 (cinquenta) minutos

Duraçăo do ano letivo: 200 (duzentos) dias

\begin{tabular}{|c|c|c|c|c|c|}
\hline \multirow{14}{*}{ 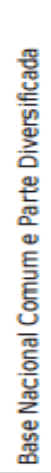 } & Áreas de Conhecimento & Disciplinas & $1^{\circ}$ ano & $2^{\circ}$ ano & $3^{2}$ ano \\
\hline & \multirow{5}{*}{ Linguagens } & Língua Portuguesa & 04 & 04 & 04 \\
\hline & & Arte & 01 & 01 & 01 \\
\hline & & Educação Fisica & 01 & 01 & 01 \\
\hline & & $\begin{array}{l}\text { Língua Estrangeira Moderna - } \\
\text { Inglês* }\end{array}$ & 01 & 01 & 01 \\
\hline & & $\begin{array}{l}\text { Língua Estrangeira Moderna - } \\
\text { Espanhol* }\end{array}$ & 01 & 01 & 01 \\
\hline & \multirow{3}{*}{ Ciências da Natureza } & Fisica & 02 & 02 & 03 \\
\hline & & Química & 02 & 03 & 02 \\
\hline & & Biologia & 03 & 02 & 02 \\
\hline & Matemática & Matemática & 04 & 04 & 04 \\
\hline & \multirow{4}{*}{ Ciências Humanas } & Geografia & 02 & 02 & 02 \\
\hline & & História & 02 & 02 & 02 \\
\hline & & Filosofia & 01 & 01 & 01 \\
\hline & & Sociologia & 01 & 01 & 01 \\
\hline \multirow{3}{*}{\multicolumn{2}{|c|}{ Totais de Cargas Horárias }} & Semanal em h/a & 25 & 25 & 25 \\
\hline & & Anual em h/a & 1000 & 1000 & 1000 \\
\hline & & Anual em horas & 834 & 834 & 834 \\
\hline
\end{tabular}

Fonte: http://www.spdo.ms.gov.br/diariodoe/Index/Download/DO9340_31_01_2017

3. Analisar os sentidos docentes provenientes dos discursos dos professores acerca da possibilidade de aplicabilidade do Referencial Curricular da Rede de Ensino do Mato Grosso do Sul - Ensino Médio

A professora Eni Puccineli Orlandi, homenageada no V Encontro em Análise do Discurso: Estudos Orlandianos e no III ENSAD - Encontro Nacional em Semântica e 
Análise do Discurso: Marcha, Identidade e Fronteira, divulgou a teoria da Análise do Discurso no Brasil, traduziu inúmeras obras de Pêcheux, e trouxe novas formas cientificas de fazer pesquisas em linguagem no que tange a construção do sentido. Assim para alcançar os objetivos listados, as novas formas cientificas de fazer pesquisas em linguagem apresentadas por Orlandi no evento, serão utilizadas na metodologia da pesquisa "Sentidos docentes: (des) ensino da Língua Portuguesa no ensino médio" para analisar os sentidos docentes.

\section{Metodologia}

No final dos anos 1960, Michel Pêcheux (1997a, 1997b, 1997c), então pesquisador da École Normale Supérieure (ENS Paris) propõe a teoria da análise de discurso, na França. A análise de discurso surge, com a discussão de questões que advogam contra o formalismo hermético da linguagem, questionando a negação da exterioridade. A linguagem não é mais concebida como apenas um sistema de regras formais com os estudos discursivos. A linguagem é pensada em sua prática, atribuindo valor ao trabalho com o simbólico, com a divisão política dos sentidos, visto que o sentido é movente e instável. O objeto de apreciação de estudo deixa de ser a frase, e passa a ser o discurso, uma vez que foge da apreciação palavra por palavra na interpretação como uma sequência fechada em si mesma.

A análise de discurso francesa se constitui como uma disciplina de confluência, uma vez que se inscreve em um lugar em que se juntam três regiões de conhecimentos, quais sejam: materialismo histórico, como uma teoria das formações sociais, inclui-se então a ideologia; a linguística, como teoria dos mecanismos sintáticos e dos processos de enunciação; e por fim, a teoria do discurso, como determinação histórica dos processos semânticos.

É no discurso, precisamente, que se concentram, se intrincam e se confundem, como um verdadeiro nó, as questões relativas à língua, à história e ao sujeito. A Análise de Discurso, como seu próprio nome indica, não trata da língua, não trata da gramática, embora todas essas coisas the interessem, ela trata do discurso. E a palavra discurso, etimologicamente, tem em si a ideia de curso, de percurso, de correr por, de movimento. O discurso é assim palavra em movimento, prática de linguagem: com o estudo do discurso observa-se o homem falando (ORLANDI, 2007, p. 15).

Orlandi (2007, p. 86) caracteriza o discurso em discurso autoritário, discurso polêmico e discurso lúdico:

a. Discurso autoritário: aquele em que a polissemia é contida, o referente está apagado pela relação de linguagem que se estabelece e o locutor se coloca como agente exclusivo, apagando também sua relação com o interlocutor;

b. Discurso polêmico: aquele em que a polissemia é controlada, o referente é disputado pelos interlocutores, e estes se mantêm em presença, numa relação tensa de disputa pelos sentidos;

c. Discurso lúdico: aquele em que a polissemia está aberta, o referente está presente como tal, sendo que os interlocutores se expõem aos efeitos dessa presença inteiramente não regulando sua relação com os sentidos $(2007$, p. 86).

É na formação discursiva que encontramos a paráfrase e a polissemia enquanto processos de significação e memória, paráfrase porque tudo já foi dito, apenas está sendo dito de maneira sinônima, todavia ao redizer a construção do sentido se move possibilitando novos sentidos, daí o caráter polissêmico. 
A análise de discurso busca compreender o discurso na singularidade de sua situação, a condição de sua existência, na correlação com outros discursos e enunciados. Para Bakhtin, a ideia de enunciação também serviu para designar o discurso escrito. $\mathrm{Na}$ obra desse autor, os textos são considerados atos de fala impressos e, então, sujeitos aos mesmos princípios da interação verbal presentes no diálogo. Por meio do emprego de conceitos como dialogismo, polifonia e heteroglossia, mostrou que, sob as palavras de alguém, ressoa a voz de outro, e estas diferentes vozes que podem ser ouvidas em um texto. Em muitos sentidos, as perspectivas abertas por Bakhtin para os estudos da linguagem sugerem que também os textos são um produto da interação social, não só determinados pela situação imediata ou pelo contexto que constitui o conjunto das condições de vida de uma determinada comunidade linguística, como também feitos para serem apreendidos de maneira ativa, para serem estudados e comentados.

Considera-se a Análise do Discurso como possibilidade de captar o sentido não explícito no discurso. Conforme já mencionado, por meio da Análise do Discurso, pretende-se seguir um percurso metodológico: apresentação do projeto de pesquisa para os docentes; coleta de discurso de professores que ministram a disciplina de Língua Portuguesa no ensino médio; recorte e agrupamento dos enunciados coletados; classificação dos discursos quanto à especificidade dos sentidos produzidos; e por fim a análise dos discursos.

Enfim, para destecer alguns fios no discurso dos docentes, será utilizado o arcabouço teórico da Análise do Discurso de linha francesa, por meio de autores como Pêcheux (1997a, 1997b, 1997c) e Orlandi (2004, 2005a, 2005b, 2007, 2012), partindo da compreensão de que o sujeito, perpassado pelo inconsciente, se constitui na e pela linguagem.

\section{Resultados esperados}

A disciplina de Língua Portuguesa encontra-se abrigada na área de Linguagens, Códigos e suas Tecnologias, de acordo com os Parâmetros Curriculares Nacionais do Ensino Médio - PCNEM (BRASIL, 1998). O ensino da disciplina de Língua Portuguesa no ensino médio tem sido motivo de debates teóricos e metodológicos, por conta dos resultados apresentados, desde a última década, por alguns sistemas de avaliação educacional tais como o ENEM - Exame Nacional do Ensino Médio e o SAEB - Sistema de Avaliação da Educação Básica, os quais, vêm registrando limitações dos egressos da educação básica quanto à leitura e à escrita em língua materna, fato que justifica pesquisas nessa temática e ainda, as recentes alterações na Matriz Curricular do Ensino Médio na Rede Estadual de Ensino de Mato Grosso do Sul.

Por conta disso, espera-se ao final da pesquisa "Sentidos docentes: (des) ensino da Língua Portuguesa no ensino médio" apresentar as análises dos sentidos acerca do ensino da Língua Portuguesa no Ensino Médio, da divisão da Língua Portuguesa na Matriz Curricular do Ensino Médio em Língua Portuguesa I e Língua Portuguesa II, da extinção das unidades curriculares Língua Portuguesa II e Literatura da Matriz Curricular do Ensino Médio e ainda, da possibilidade de aplicabilidade do Referencial Curricular da Rede Estadual de Ensino do Mato Grosso do Sul - Ensino Médio.

Espera-se ainda, a partir dos discursos encontrados organizar e realizar seminários de estudos para aprofundamento da temática "ensino da Língua Portuguesa no Ensino Médio" e quiçá apresentá-los no VI Encontro em Análise do Discurso: Estudos Orlandianos e no IV ENSAD - Encontro Nacional em Semântica e Análise do Discurso: Marcha, Identidade e Fronteira, eventos de grande porte a serem possivelmente organizados pela Universidade Estadual do Mato Grosso do Sul. 


\section{REFERÊNCIAS}

BRASIL. Ministério da Educação (MEC). Conselho Nacional De Educação (CNE). Diretrizes Curriculares Nacionais para o Ensino Médio. Resolução CEB n. 3, de 26 de junho de 1998. Brasília, DF: MEC/CNE, 1998. Disponível em: $<$ http://portal.mec.gov.br/cne/arquivos/pdf/rceb03 98.pdf $>$. Acesso em: SET. 2017.

Bakhtin, M. Estética da criação verbal. Tradução de Paulo Bezerra. São Paulo: Martins Fontes, 2011.

Bakhtin, M.; Volochinov, V. N. Marxismo e filosofia da linguagem. Tradução de Michel Lahud e Yara Frateschi Vieira. São Paulo: Hucitec, 1992.

ORLANDI, Eni. Discurso em Análise: sujeito, sentido, ideologia. Campinas: Pontes, 2012.

ORLANDI, Eni Pulccinelli. Interpretação: autoria, leitura e efeitos do trabalho simbólico. 4. ed. Campinas: Pontes, 2004. 156p.

ORLANDI, Eni Pulccinelli. Discurso e texto: formulação e circulação dos sentidos. Campinas, SP: Pontes, 2005a. 218p.

ORLANDI, Eni Pulccinelli. A Análise de Discurso em suas diferentes tradições intelectuais: o Brasil. In: INDURSKY, F.; FERREIRA, M.C.L. (Org.). Michel Pêcheux e a análise do discurso: uma relação de nunca acabar. São Carlos: Claraluz, 2005b. p. $75-88$.

ORLANDI, Eni Pulccinelli. Análise do Discurso: princípios e procedimentos. 6 . ed. Campinas, SP: Pontes, 2007. 100p.

ORLANDI, Eni. A história do sujeito-leitor: uma questão para a leitura. Discurso e leitura. Campinas: Pontes, 1988.

PÊCHEUX, Michel. Semântica e discurso: uma crítica à afirmação do óbvio. 3. ed. Trad. Eni Pucinelli Orlandi [et al.]. Campinas, SP: Editora da UNICAMP, 1997a. 317p.

PÊCHEUX, Michel. Análise automática do discurso. In: GADET, F.; HARK, T. (Org.). Por uma análise automática do discurso: uma introdução à obra de Michel Pêcheux. 3. ed. Trad. Bethania S. Mariani [et al.]. Campinas, SP: Editora da Unicamp, 1997b. p. 61-105.

PÊCHEUX, Michel. Discurso: estrutura ou acontecimento. Trad. Eni Puccinelli Orlandi. 3. ed. Campinas, SP: Editora da Unicamp, 1997c. 68p.

PÊCHEUX, Michel. Delimitações, Inversões, Deslocamentos. Cadernos de Estudos Linguísticos, n.19. Campinas: Unicamp. 1990, p. 7-24.

Secretaria de Educação do Estado de Mato Grosso do Sul. Resolução SED/MS 3098/2016. Disponível em: http://www.spdo.ms.gov.br/diariodoe/Index/Download/DO926305102016 Acesso em: SET. 2017.

Secretaria de Educação do Estado de Mato Grosso do Sul. Resolução SED/MS 3196/2017.

em: http://www.spdo.ms.gov.br/diariodoe/Index/Download/DO9340 $31 \quad 012017$ Acesso em: SET. 2017. 
SED/MS. Secretaria de Educação do Estado de Mato Grosso do Sul. Referencial Curricular da Rede Estadual de Ensino do Mato Grosso do Sul - Ensino Médio. Campo Grande - MS, 2012.

Recebido em: agosto de 2017.

Aprovado em: outubro de 2017.

Como citar este trabalho:

CASSOLA, R. V. Sentidos docentes: (des) ensino da língua portuguesa no ensino médio. Traços de linguagem, v. 1, n. 2, p. 35-42, 2017. 